\title{
Dynamic contour tonometry in asymmetric glaucoma patients
}

This article was published in the following Dove Press journal:

Clinical Ophthalmology

10 April 2012

Number of times this article has been viewed

\section{Emilio Rintaro Suzuki Jr' Cibele Lima Belico Suzuki' Danielle Carlier' Daniele Penha' Marta dos Anjos Rodrigues Parchen' Wagner Duarte Batista' Joao Agostini Netto ${ }^{2}$}

'Glaucoma Service, ${ }^{2}$ Department of Ophthalmology, Santa Casa de Belo Horizonte, MG, Brazil
Correspondence: Emilio Rintaro Suzuki Jr Av Doutor Cristiano Guimaraes 1994 CEP 31720-300, Belo Horizonte, MG, Brazil

Tel +553 I 344I $5 \mid 52$

Fax +553191692016

Email emilio.suzuki@uol.com.br
Background: The purpose of this study was to determine any difference in dynamic contour tonometry and ocular pulse amplitude in asymmetric glaucoma patients with the same applanation intraocular pressure.

Methods: This is a prospective, observational study of 30 glaucoma patients and 11 controls from June 2007 to February 2008. Most of the glaucoma patients were on prostaglandin analog treatment.

Results: Mean applanation intraocular pressure in the control group was $14.28 \mathrm{mmHg}$ for the right eye and $14.10 \mathrm{mmHg}$ for the left eye $(P>0.05)$. Corneal thickness was $519.10 \mu \mathrm{m}$ for the right eye and $511.07 \mu \mathrm{m}$ for the left eye $(P>0.05)$. Mean dynamic contour tonometry intraocular pressure was $17.28 \mathrm{mmHg}$ for the right eye and $17.25 \mathrm{mmHg}$ for the left eye $(P>0.05)$. Mean ocular pulse amplitude was $2.80 \mathrm{mmHg}$ for the right eye and $2.92 \mathrm{mmHg}$ for the left eye $(P>0.05)$.

Conclusion: No differences in ocular pulse amplitude were found between the two groups and between the worst and the best eye. In spite of there being no difference in ocular pulse amplitude, dynamic contour tonometry intraocular pressure was $2.44 \mathrm{mmHg}$ higher in the worst eye than in the best eye in the glaucoma patients, even with the same applanation intraocular pressure. Further studies are needed to confirm if this difference is related to glaucoma progression or a worst prognosis and whether it can be considered to be a new risk factor.

Keywords: dynamic contour tonometry, central cornea thickness, assymetric glaucoma

\section{Introduction}

Glaucoma is a multifactorial disease associated with optic nerve damage, visual field defects, and often elevated intraocular pressure. Intraocular pressure remains the major risk factor for onset of glaucoma and its progression. Nevertheless, there are several aspects of intraocular pressure that have been researched to clarify its role in the pathology of glaucoma. Central cornea thickness, bioelasticity, and intraocular pulse amplitude are points of special interest. ${ }^{1}$ Dynamic contour tonometry is a device capable of measuring intraocular pressure with less central cornea influence and ocular pulse amplitude. ${ }^{2}$ The main purpose of this study is to determine if there can be any differences in dynamic contour tonometry and ocular pulse amplitude in asymmetric glaucoma patients with the same applanation intraocular pressure.

\section{Materials and methods}

This was a prospective, observational study of 30 glaucoma patients and 11 controls between June 2007 and February 2008. Inclusion criteria were: the same intraocular 
Table I Ocular parameters in control subjects

\begin{tabular}{llllll}
\hline & n & Right & Left & Difference & $\boldsymbol{P}$ \\
\hline Applanation IOP $(\mathrm{mmHg})$ & II & 14.28 & 14.10 & 0.18 & $>0.05$ \\
DCT IOP $(\mathrm{mmHg})$ & II & 17.28 & 17.25 & 0.03 & $>0.05$ \\
OPA $(\mathrm{mmHg})$ & II & 2.80 & 2.92 & 0.12 & $>0.05$ \\
CCT $(\mu \mathrm{m})$ & II & 519.10 & 511.07 & 8.03 & $>0.05$ \\
\hline
\end{tabular}

Abbreviations: CCT, central corneal thickness; DCT, dynamic contour tonometry; IOP, intraocular pressure; OPA, ocular pulse amplitude.

pressure on applanation tonometry in both eyes; a difference of $\geq 6 \mathrm{~dB}$ in mean deviation of visual field; a difference $\geq 0.2$ in cup-to-disc ratio; and a dynamic contour tonometry measurement quality score reading of 1 or 2 in glaucoma patients. Dynamic contour tonometry intraocular pressure, ocular pulse amplitude, corneal thickness, applanation tonometry, and fundus examination was undertaken in both groups. Most of the glaucoma patients were on prostaglandin analog treatment. Statistical analyses were performed using the Kolmogorov-Smirnov and Shapiro-Wilk tests and Pearson's linear correlation. Results with $P<0.05$ were accepted as being statistically significant. The study was conducted in accordance with the clinical research regulations prevailing in Brazil (resolution 196/96) and with the ethical standards stated in the 1964 Declaration of Helsinki regarding ethical principles for medical research involving human subjects.

\section{Results}

The mean age of participants in this study was 61.23 years. Twenty-four female and 17 male patients were enrolled. Twenty-three patients were Hispanic and 18 were Black.

In the controls, mean applanation intraocular pressure was $14.28 \mathrm{mmHg}$ for the right eye and $14.10 \mathrm{mmHg}$ for the left eye $(P>0.05)$. Corneal thickness was $519.10 \mu \mathrm{m}$ for the right eye and $511.07 \mu \mathrm{m}$ for the left eye $(P>0.05)$. Mean dynamic contour tonometry intraocular pressure was $17.28 \mathrm{mmHg}$ for the right eye and $17.25 \mathrm{mmHg}$ for the left eye $(P>0.05)$. Mean ocular pulse amplitude was $2.80 \mathrm{mmHg}$ for the right eye and $2.92 \mathrm{mmHg}$ for the left eye $(P>0.05$, Table 1$)$.
In glaucoma patients, mean applanation intraocular pressure was $15.70 \mathrm{mmHg}$ for the worst eye and $14.93 \mathrm{mmHg}$ for the best eye ( $P=0.078$, Table 2, Figure 1). Mean dynamic contour tonometry intraocular pressure was $20.63 \mathrm{mmHg}$ for the worst eye and $18.19 \mathrm{mmHg}$ for the best eye. This difference was statistically significant $(P<0.05$, Table 3 , Figure 2). Mean ocular pulse amplitude was $2.76 \mathrm{mmHg}$ for the worst eye and $2.68 \mathrm{mmHg}$ for the best eye $(P=0.501$, Table 4, Figure 3). Corneal thickness was $516.60 \mu \mathrm{m}$ for the worst eye and $507.07 \mu \mathrm{m}$ for the best eye $(P>0.05$, Table 5, Figure 4).

\section{Discussion}

Some studies report that thinner corneas are more likely to be associated with glaucoma probably because of underestimation of intraocular pressure measurement by applanation tonometry. The Ocular Hypertension Treatment Study showed that decreased corneal thickness is associated with a higher risk of development of glaucoma in patients with ocular hypertension. ${ }^{3}$ Studies regarding elasticity and other properties of the cornea are still unclear. The pulsatility of intraocular pressure and its correlation with glaucoma also remains unclear. Some authors have reported different results for ocular pulse amplitude measurement.

Weizer et al showed that increased ocular pulse amplitude seems to correlate with less severe glaucoma and with increased central corneal thickness. ${ }^{4}$ Punjabi et al published a study comparing intraocular pressure and ocular pulse amplitude in different types of glaucoma using dynamic contour tonometry and concluded that ocular pulse amplitude was higher in patients with ocular hypertension. ${ }^{5}$ Romppainen et al found that subjects with ocular hypertension showed significantly higher ocular pulse amplitude values $(3.6 \pm 1.3 \mathrm{mmHg})$ than healthy eyes $(3.1 \pm 1.4 \mathrm{mmHg})$ and eyes with low-tension glaucoma $(2.9 \pm 1.4 \mathrm{mmHg})$. After trabeculectomy, the values were significantly lower $(2.4 \pm 1.3 \mathrm{mmHg})$ than in healthy eyes. ${ }^{6}$ Stalmans et al studied the ocular pulse amplitude in normal tension and

Table 2 Applanation tonometry in glaucoma patients $(\mathrm{mmHg})$

\begin{tabular}{llllllll}
\hline Applanation tonometry & $\mathbf{n}$ & Mean & Median & SD & Min/max & Kolmogorov-Smirnov & Shapiro-Wilk \\
\hline Worst eye & 30 & 15.70 & 15.00 & 3.57 & $10.0 / 25.0$ & 0.112 & 0.106 \\
Best eye & 30 & 14.93 & 15.00 & 2.91 & $10.0 / 22.0$ & 0.200 & 0.250 \\
Worst, best & 30 & 0.767 & 0.000 & 2.315 & $-3.0 / 10.0$ & 0.000 & 0.000 \\
Par & $\mathbf{n}$ & Pearson & $\mathbf{P}$ & Wilcoxon & & & \\
Worst, best & 30 & 0.764 & 0.000 & 0.078 & & &
\end{tabular}

Abbreviations: Min, minimum; Max, maximum; SD, standard deviation. 
Applanation IOP

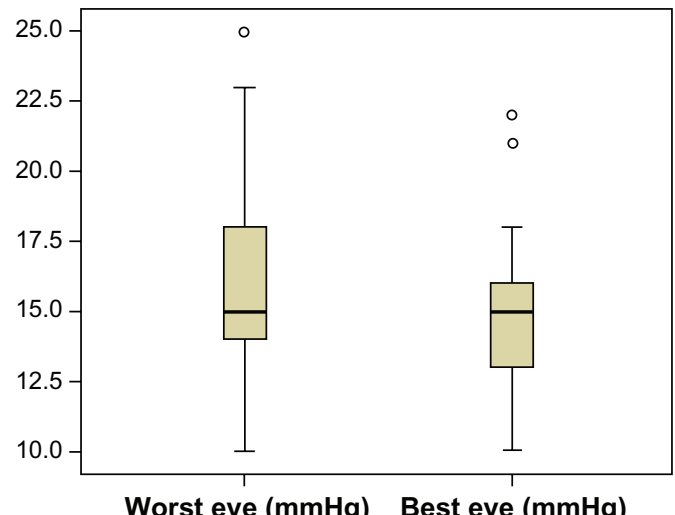

Worst eye $(\mathrm{mmHg}) \quad$ Best eye $(\mathrm{mmHg})$
Applanation IOP

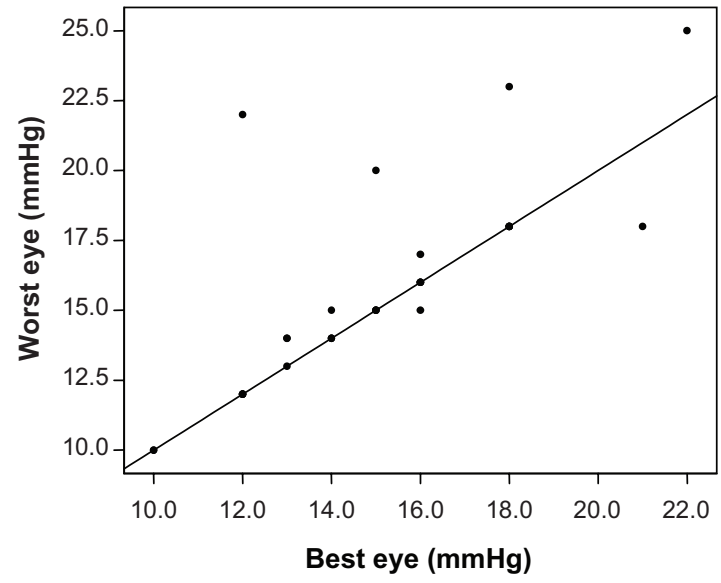

Figure I The mean applanation IOP was $15.70 \mathrm{mmHg}$ for the worst eye and $14.93 \mathrm{mmHg}$ for the best eye $(P=0.078)$.

Abbreviation: IOP, intraocular pressure.

DCT IOP

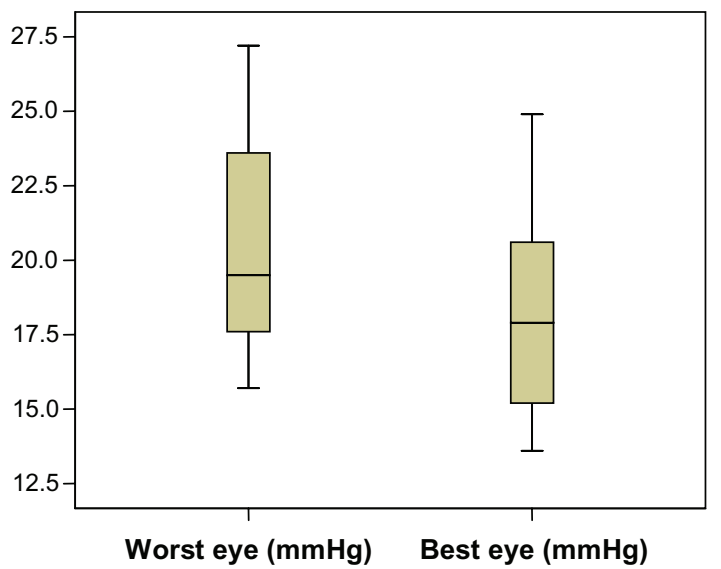

DCT IOP

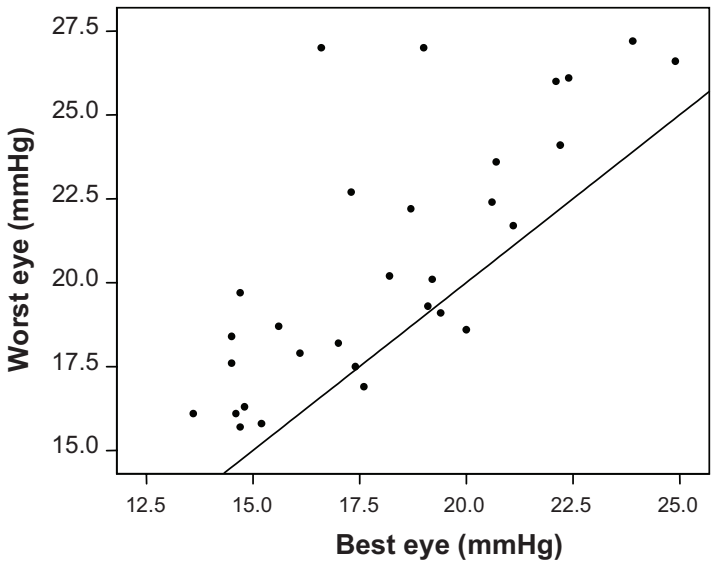

Figure 2 The mean DCT IOP was $20.63 \mathrm{mmHg}$ for the worst eye and $18.19 \mathrm{mmHg}$ for the best eye $(P<0.05)$.

Abbreviations: DCT, dynamic contour tonometry; IOP, intraocular pressure.

Table 3 Dynamic contour tonometry intraocular pressure $(\mathrm{mmHg})$

\begin{tabular}{llllllll}
\hline DCT IOP & $\mathbf{n}$ & Mean & Median & SD & Min/max & Kolmogorov-Smirnov & Shapiro-Wilk \\
\hline Worst eye & 30 & 20.63 & 19.50 & 3.82 & $15.70 / 27.20$ & 0.111 & 0.012 \\
Best eye & 30 & 18.19 & 17.90 & 3.09 & $13.60 / 24.90$ & 0.200 & 0.189 \\
Worst, best & 30 & 2.44 & 1.85 & 2.47 & $-1.40 / 10.40$ & 0.116 \\
Par & $\mathbf{n}$ & Pearson & $\mathbf{P}$ & Wilcoxon & t-test & & \\
\hline Worst, best & 30 & 0.763 & 0.000 & 0.000 & 0.000 & \\
\hline
\end{tabular}

Abbreviations: Min, minimum; Max, maximum; SD, standard deviation; DCT, dynamic contour tonometry; IOP, intraocular pressure.

Table 4 Ocular amplitude pulse $(\mathrm{mmHg})$

\begin{tabular}{|c|c|c|c|c|c|c|c|}
\hline Ocular amplitude pulse & $\mathbf{n}$ & Mean & Median & SD & Min/max & Kolmogorov-Smirnov & Shapiro-Wilk \\
\hline Worst eye & 30 & 2.76 & 2.65 & 1.03 & $1.00 / 4.50$ & 0.200 & 0.166 \\
\hline Best eye & 30 & 2.68 & 2.55 & 1.08 & I. $10 / 5.00$ & 0.200 & 0.117 \\
\hline Worst, best & 30 & 0.087 & 0.150 & 0.697 & $-1.70 / 1.40$ & 0.200 & 0.211 \\
\hline Par & $\mathbf{n}$ & Pearson & $P$ & Wilcoxon & t-test & & \\
\hline Worst, best & 30 & 0.785 & 0.000 & 0.276 & 0.501 & & \\
\hline
\end{tabular}

Abbreviations: Min, minimum; Max, maximum; SD, standard deviation. 
OPA

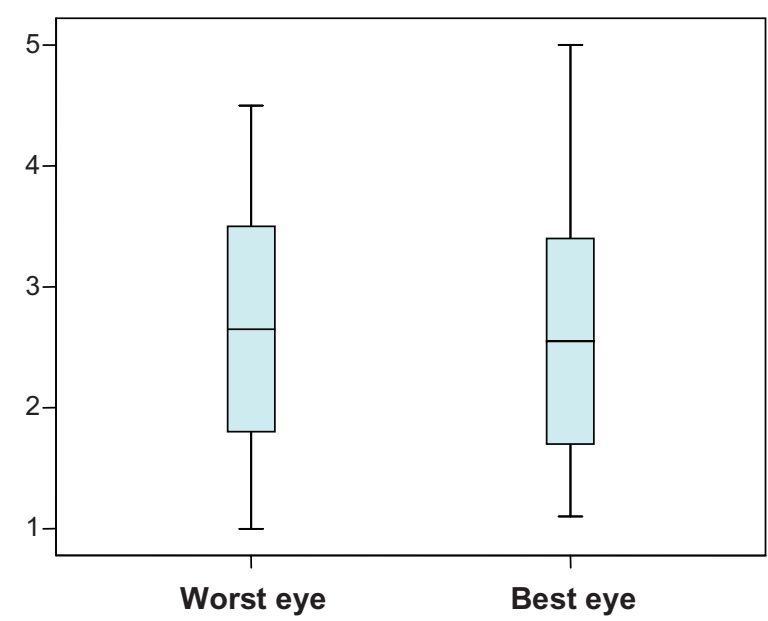

OPA

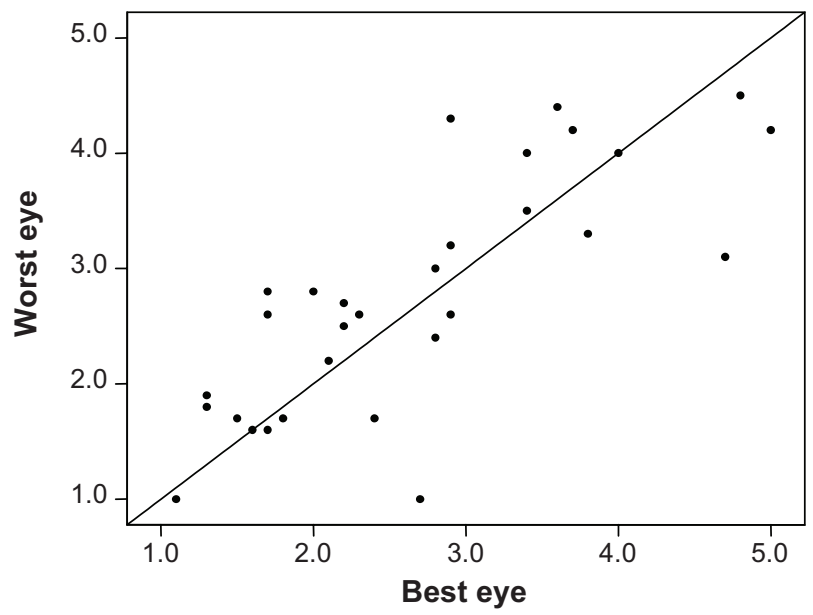

Figure 3 The mean OPA was $2.76 \mathrm{mmHg}$ for the worst eye and $2.68 \mathrm{mmHg}$ for the best eye $(P=0.50 \mathrm{I})$. Abbreviation: OPA, ocular pulse amplitude.
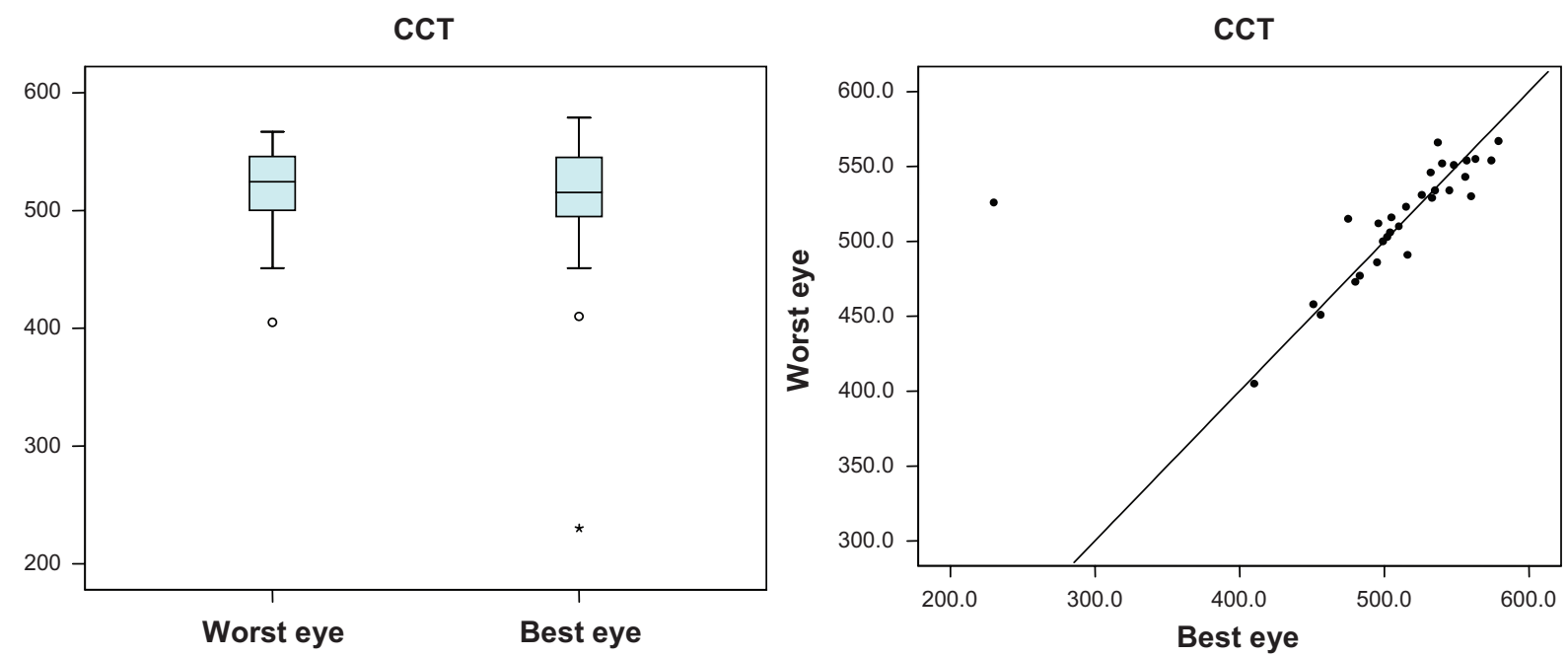

Figure 4 Corneal thickness was $516.60 \mu \mathrm{m}$ for the worst eye and $507.07 \mu \mathrm{m}$ for the best eye $(P<0.05)$. Abbreviation: $\mathrm{CCT}$, central corneal thickness.

Table 5 Central corneal thickness $(\mu \mathrm{m})$

\begin{tabular}{llllllll}
\hline $\begin{array}{l}\text { Central corneal } \\
\text { thickness }\end{array}$ & $\mathbf{n}$ & Mean & Median & SD & Mín/max & $\begin{array}{l}\text { Kolmogorov- } \\
\text { Smirnov }\end{array}$ & $\begin{array}{l}\text { Shapiro- } \\
\text { Wilk }\end{array}$ \\
\hline Worst eye & 30 & 516.60 & 524.50 & 37.33 & $405.0 / 567.0$ & 0.200 & 0.044 \\
Best eye & 30 & 507.07 & 515.50 & 65.07 & $230.0 / 579.0$ & 0.006 & 0.000 \\
Worst, best & 30 & 9.53 & -0.50 & 55.98 & $-30.0 / 296.0$ & 0.000 & 0.000 \\
Par & $\mathbf{n}$ & Pearson & $\mathbf{P}$ & Wilcoxon & t-test & & \\
\hline Worst, best & 30 & 0.514 & 0.004 & 0.953 & 0.359 & \\
\hline
\end{tabular}

Abbreviations: Min, minimum; Max, maximum; SD, standard deviation. 
primary open-angle glaucoma and concluded that ocular pulse amplitude was reduced in patients with primary openangle glaucoma and normal tension compared with healthy controls. Ocular pulse amplitude is influenced by intraocular pressure, but not by corneal thickness. ${ }^{7}$ Sullivan-Mee et al in a very similar study of patients with asymmetric glaucoma demonstrated that dynamic contour tonometry intraocular pressure was significantly higher in eyes with a higher AGIS score than in eyes with a lower AGIS score (16.3 versus $15.5 \mathrm{mmHg}, P=0.004)$, but applanation intraocular pressure was not significantly different in the same eyes $(14.5 \mathrm{mmHg}$ versus $14.4 \mathrm{mmHg}, P=0.56$ ).

These findings suggest that dynamic contour tonometry intraocular pressure is more related to the extension of damage of glaucoma than is applanation intraocular pressure. The most likely explanation for these results is that applanation intraocular pressure systematically underestimates intraocular pressure compared with dynamic contour tonometry intraocular pressure. ${ }^{8}$

In our study, ocular pulse amplitude was similar in both asymmetric eyes and in controls. However, dynamic contour tonometry intraocular pressure was significantly different between the worst and best eye in glaucoma patients. We found a $2.44 \mathrm{mmHg}$ higher dynamic contour tonometry intraocular pressure in the worst eye than in the best eye, despite the same applanation intraocular pressure. However, no significant dynamic contour tonometry difference was observed in the controls.

Perhaps these results can be explained in light of the underestimation of applanation tonometry intraocular pressure compared with dynamic contour tonometry intraocular pressure. Further, some as yet unknown corneal factors could be responsible for this difference between worst and best eyes with glaucoma. This difference could represent a new risk factor for glaucoma prognosis, onset, or progression.

\section{Conclusion}

No differences in ocular pulse amplitude were found between the groups or between the worst and the best eye. In spite of the lack of difference in ocular pulse amplitude, dynamic contour tonometry intraocular pressure was $2.44 \mathrm{mmHg}$ higher in the worst eye than in the best eye in glaucoma patients, even with the same applanation intraocular pressure. Further studies are needed to confirm if this difference is related to glaucoma progression and/or a worse prognosis, and whether dynamic contour tonometry intraocular pressure should be considered as a new risk factor.

\section{Disclosure}

The authors report no conflicts of interest in this work.

\section{References}

1. Hager A, Loge K, Schroeder B, Füllhas MO, Wiegand W. Effect of central corneal thickness and corneal hysteresis on tonometry as measured by dynamic contour tonometry, ocular response analyzer, and Goldmann tonometry in glaucomatous eyes. J Glaucoma. 2008;17(7):604.

2. Boehm AG, Weber A, Pillunat LE, Koch R, Spoerl E. Dynamic contour tonometry in comparison to intracameral IOP measurements. Invest Ophthalmol Vis Sci. 2008;49(6):2472-2477.

3. Brandt JD, Beiser JA, Kass MA, Gordon MO. Central corneal thickness in the Ocular Hypertension Treatment Study (OHTS). Ophthalmology. 2001;108(10):1779-1788.

4. Weizer JS, Asrani S, Stinnett SS, Herndon LW. The clinical utility of dynamic contour tonometry and ocular pulse amplitude. J Glaucoma. 2007;16(8):700-703.

5. Punjabi OS, Ho HK, Kniestedt C, Bostrom AG, Stamper RL, Lin SC. Intraocular pressure and ocular pulse amplitude comparisons in different types of glaucoma using dynamic contour tonometry. Curr Eye Res. 2006;31(10):851-862.

6. Romppainen T, Kniestedt C, Bachmann LM, Stürmer J. Ocular pulse amplitude: a new biometrical parameter for the diagnose of glaucoma? Ophthalmologe. 2007;104(3):230-235. German.

7. Stalmans I, Harris A, Vanbellinghen V, Zeyen T, Siesky B. Ocular pulse amplitude in normal tension and primary open angle glaucoma. J Glaucoma. 2008;17(5):403-407.

8. Sullivan-Mee M, Halverson KD, Qualls C. Clinical comparison of Pascal dynamic contour tonometry and Goldmann applanation tonometry in asymmetric open-angle glaucoma. J Glaucoma. 2007;16(8):694-699.
Clinical Ophthalmology

\section{Publish your work in this journal}

Clinical Ophthalmology is an international, peer-reviewed journal covering all subspecialties within ophthalmology. Key topics include: Optometry; Visual science; Pharmacology and drug therapy in eye diseases; Basic Sciences; Primary and Secondary eye care; Patient Safety and Quality of Care Improvements. This journal is indexed on

Submit your manuscript here: http://www.dovepress.com/clinical-ophthalmology-journal

\section{Dovepress}

PubMed Central and CAS, and is the official journal of The Society of Clinical Ophthalmology (SCO). The manuscript management system is completely online and includes a very quick and fair peer-review system, which is all easy to use. Visit http://www.dovepress.com/ testimonials.php to read real quotes from published authors. 